\title{
Tools to operate and manage early warning systems for natural hazards monitoring in El Salvador
}

Jacqueline Yamileth Rivera

\begin{abstract}
Background: This article explores the concerns from the institutions to include information from the field into geographical information systems (GIS). This task is becoming an essential action to strengthen and speed up the response to an imminent threat. Specially creating strategies supported by national plans such as risk reduction national plans, and climate change national plans among others.

Methods: The research is based on the case of the Ministry of Environment and Natural Resources of El Salvador (MARN for its acronym in Spanish) that has performed various actions in monitoring disasters. The telemetry technology has started to be one of the main system for data collection. Despite the fact that El Salvador is a developing country, the first steps have been performed to form an integrated system.

Results: To develop an effective EWS in the recent year the implementation of GIS is one of the tool to manage data. Among this, different software classified in principle as an open or proprietary source exists. The research explain how the monitoring center implements such a software as one of the main bases for the daily tasks that needs to be accomplished.

Discussion: Therefore, we discuss two case examples to elaborate on the importance of this study (El Salvador case and Korean case). Presenting the procedures of both countries, the centers have started to use different tools that combine the use of open source software and proprietary software to develop applications that are easily understood by people and offers easy access and transmission in real time.

Conclusion: The final product proposes is to propose an integrated and comprehensive system, sharing information in the shortest time possible, and achieving a big database available to make risk assessments would be the main goals of such a system.
\end{abstract}

Keywords: Early warning systems, Geographical information systems, Open or proprietary software, Natural threats

\section{Introduction}

Natural disasters such as tsunamis, earthquakes, volcanic eruptions, etc. are produced by natural forces and induced by internal dynamic process in the earth. The ones generated by dynamic process on Earth surface can be landslides, mudslides and avalanches. In addition, another type of disaster can be generated by meteorological or hydrological phenomena such as hurricanes, tropical storms, and drought.

Latin America and the Caribbean region is classified among the regions with high vulnerability to suffer natural disasters. The estimated economic lost per year

Correspondence: jacque.rivera87@gmail.com

Ministry of Environment and Natural Resources, San Salvador, El Salvador due to the consequences of the disaster is 2000 million dollars per year. Based on this information, Latin-American countries are the most vulnerable on the planet, and more specific, El Salvador ranks among the ten most vulnerable countries [15].

The geographical characteristic of El Salvador, located in the tropical climate zone and in the Ring of Fire, ${ }^{1}$ makes the country to be in a constantly zone risk to natural hazards. It is characterized by intense seismic and volcanic activity generated by the subduction and the activation of both geological faults. Besides this, meteorological events affects the country year by year where due to its location hurricanes, tropical storms, seasonal rains and intense rainfall events occurs very frequently. Additionally, due to 
the accelerated climate change, meteorological events are becoming more frequent and destructive. One of the more destructive cases was recorded between October and November 1998: the hurricane Mitch, hitting the countries in Central America, causing several damages to lives as well as infrastructure.

The rainfall patterns have been changing in the last 20 years due to the effect of global climate change. During the recent years, rainfall records indicate that storms intensity is higher and duration is shorter compared to similar events in the past. Those elements cause flash floods mainly in the urban areas and waterlogging for long periods in the agricultural areas. (See Fig. 1. Extreme Events in El Salvador 1960 - 2011)

Approximately $90 \%$ of El Salvador's lands are at risk while $95 \%$ of the country's population are living in risk zones and $96 \%$ of the GDP is produced in such zones. ${ }^{2}$ (See Table 1. Economic losses caused by natural disasters in El Salvador) [7]. Hence, it is of great importance to develop Early Warning Systems (EWS) in order to be able to decrease the loss of life in future disasters. Therefore, EWS were developed to warn the possibility of a natural event that could cause a disaster in advance with the aim of decreasing the vulnerability. EWS systems are designed and operated to alert the population when an event is in the proximities to immediately make it less vulnerable and trying to anticipate natural events. Those events that are in interaction with vulnerabilities can lead to a disaster [1].

The bases to establish the four elements of humancentered theory related to early warning systems have been set by the United Nations Office for Disaster Risk Reduction (UNISDR). The aim of such elements is to strengthen individual capacities and communities at risk to respond on time to a threat [9]. (See Fig. 2. Four Elements of People-centred Early Warning Systems)
Table 1 Economic losses caused by natural disasters in El Salvador

\begin{tabular}{lll}
\hline Disaster & Date & Damage (000 US\$) \\
\hline Earthquake (seismic activity) & $10 / 10 / 1986$ & 1500000 \\
Earthquake (seismic activity) & $13 / 01 / 2001$ & 1500000 \\
Flood & $09 / 2011$ & 1000000 \\
Storm & $07 / 11 / 2009$ & 939000 \\
Storm & $25 / 10 / 1998$ & 388100 \\
Storm & $01 / 10 / 2005$ & 355700 \\
Earthquake (seismic activity) & $13 / 02 / 2001$ & 348500 \\
Flood & $17 / 09 / 1982$ & 280000 \\
Drought & $05 / 1998$ & 170000 \\
Earthquake (seismic activity) & $03 / 05 / 1965$ & 35000 \\
\hline
\end{tabular}

Source: "EM-DAT: The OFDA/CRED International Disaster Database. http://www.emdat.be/database Université Catholique de Louvain Brussels Belgium". Created on: Oct-23-2014. Data version: v12.07

El Salvador has performed various actions in monitoring disasters by locating automated sensors in the field as well as upgrading the instruments continuously. The telemetry technology has started to be one of the main system for data collection.

According to historical records, since 1983 a telemetric network collecting data from the field was implemented for monitoring the seismic risk in order to facilitate real-time response [14]. In 1998, due to the effects caused by hurricane Mitch, the central government in El Salvador installed telemetric stations with satellite transmission systems to record information about precipitation, wind, river water levels, and temperature. Nowadays, the mentioned systems are operating and expanding along the country. Meanwhile, different areas were functioning separately for more than 15 years.

The Ministry of Environment and Natural Resources of El Salvador (MARN for its acronym in Spanish)

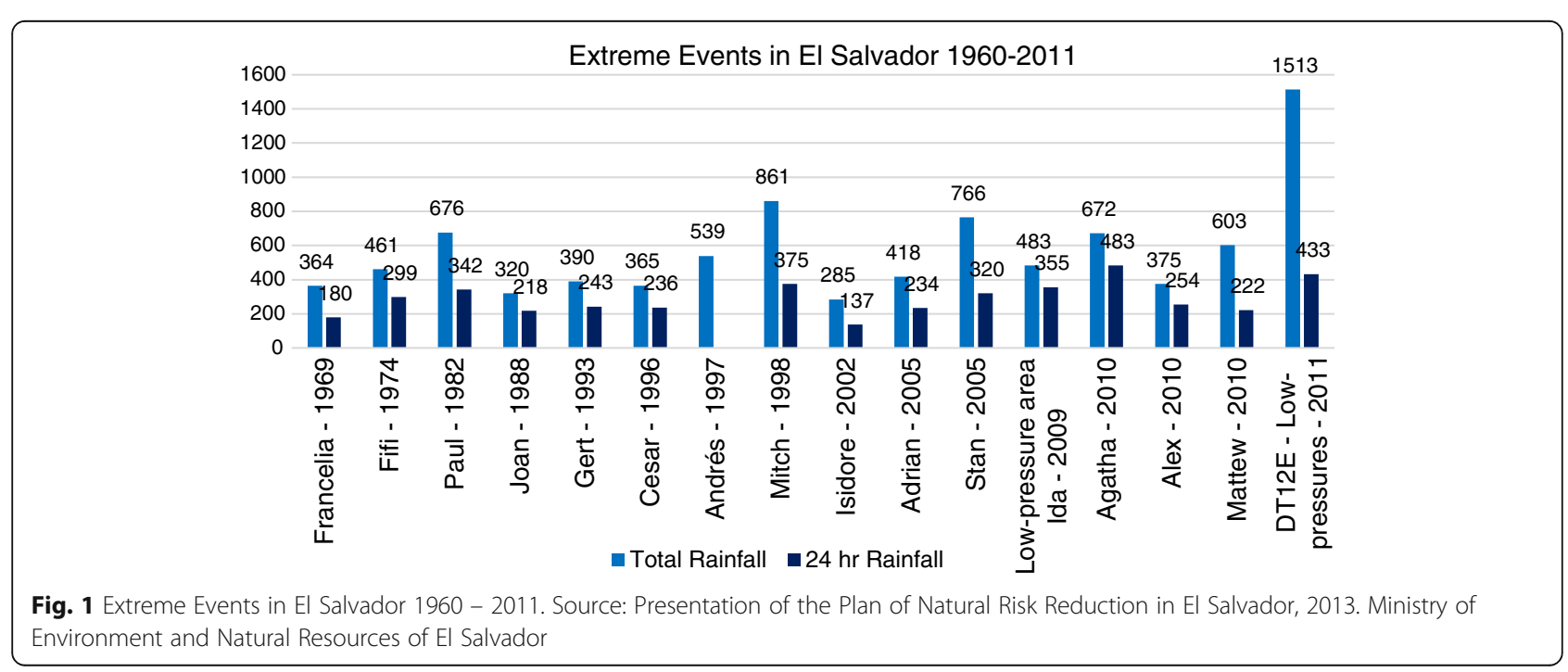




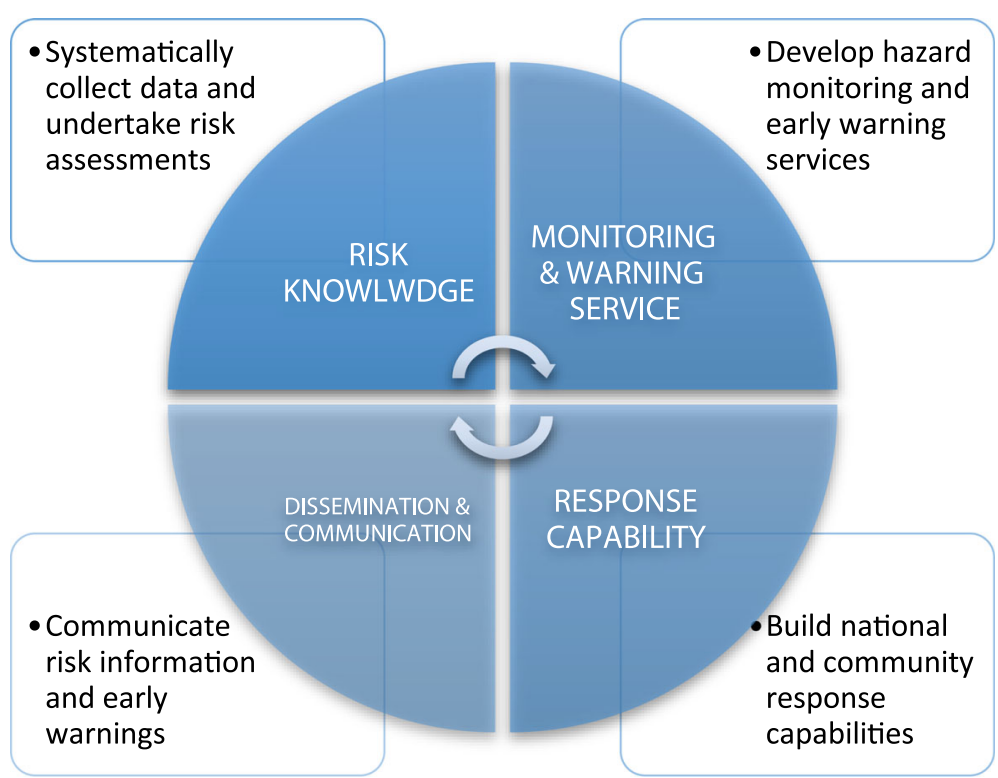

Fig. 2 Four Elements of People-centred Early Warning Systems. Source: UN/ISDR Platform for the Promotion of Early Warning

defined to implement a culture for recovering the environment and reducing environmental risk. One of the institution vision is to focus on the EWS as a system implemented to alert in advance from a potential or imminent risk in order to protect life and property. There are different types of early warning systems based on the use of measuring devices in the field, some of them are with automatic sensors while others use satellite technology.

The main reason to establish a monitoring center for natural hazards in El Salvador is the scientific approach application of the early warning systems to manage the telemetric station network and monitoring natural hazards in El Salvador. Since 2001, the center is implementing different technology devices, software among other element for the vigilance and to develop the most accurate forecast information, besides other activities related to the risk assessment.

The Monitoring Center is composed by different areas, the Hydrological, Meteorological, Landslide, Oceanography, Volcanology, and Seismic area (Fig. 3). It involves the communication with the rest of the state, local governments and other regional actors such as civil society, business community, universities and the population in general. The communication with local observers in the risk areas is an essential element in the system in order to strengthen this communication and to make it faster and effective.

The information is shared with the public via different communication modes such as phone, radio tele-

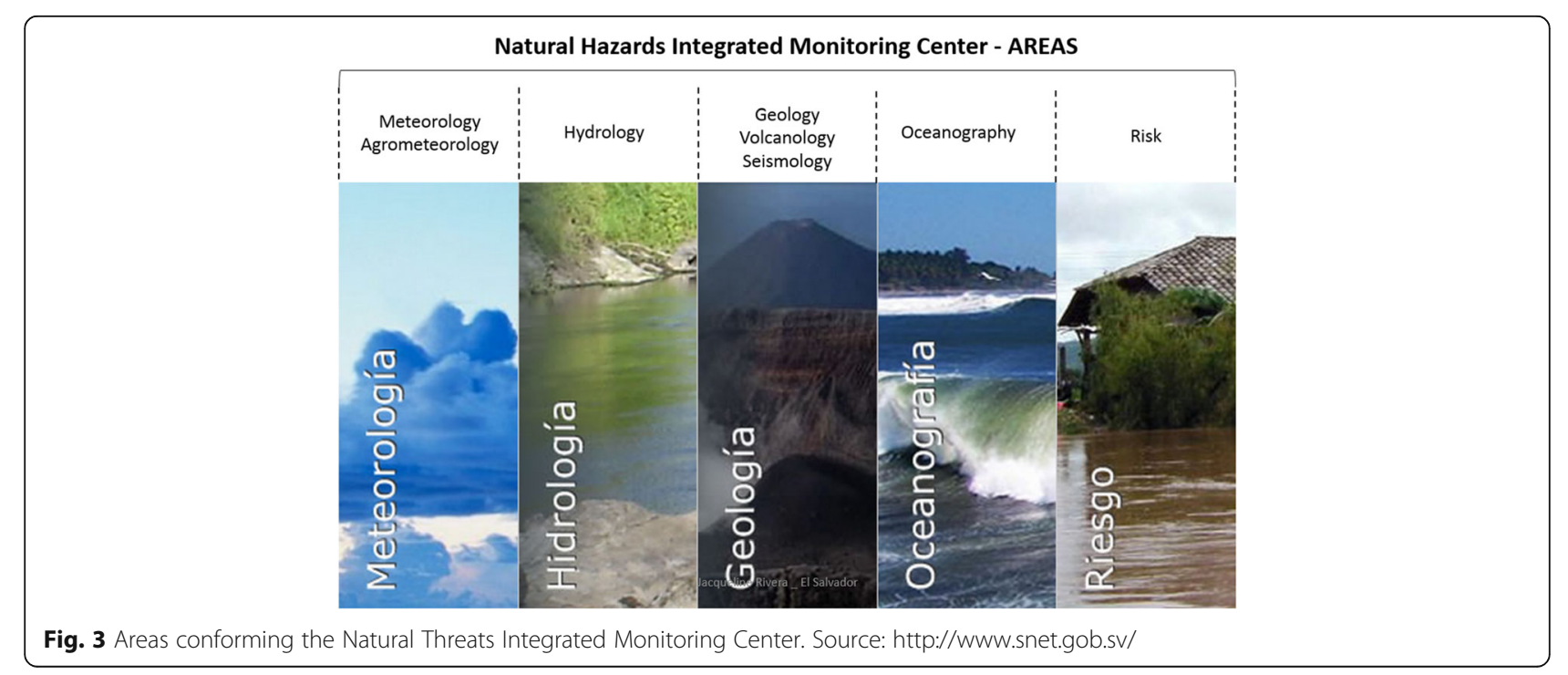


communication, social networks and websites. The aim is that communication reaches the entire population within a reasonable time, allowing preventive actions.

Large amount of data on real time is handled for managing EWS. Therefore, geographical information systems (GIS) become an optimal tool. There exist three mains aspects to highlight:

\section{- Identification of the risk - Measurement} Instrumentation: creating suitable softwares with specific characteristics and allowing accurate results on risk and vulnerability assessment are important in this stage. Currently, GIS platforms are applied to the data processes. This area must be strengthened so that the information systems can be shared between the institutions related to spatial data collection and statistical data. Finally, the identification of legal and illegal human settlements located in high-risk sectors are taken care of in this stage.

- Climate Change - Monitoring and alert: The main aim is to strengthen the existing EWS and create a more sophisticated network to measure data for specific studies. Studies related to the climate change needs data such as: evapotranspiration sensors, sensors measuring sea level, sensors for $\mathrm{CO}_{2}$ emissions, etc.

- Improving responsiveness - Broadcasting and communication: The main aim is to strengthen the existing EWS, improve communication with communities and institutions. Mainly by installing radio communication network and sensors with alarms.

Through a Risk Reduction Program in 2011 a powerful data center was established to support and improve the communication capability with the aim of achieving considerable benefits to increase the capacity, speed of storage and access to information.

There components that need data management by GIS and information and communication technology (ICT) include:

- Dynamic Risk Atlas: To improve the monitoring and analysis of territorial information online.

- Early Warning Systems in priority areas: Where early warning systems (EWS) for floods and landslides will be established.

- Integration perspective of risk reduction in public investment: investments on infrastructure, housing and mitigation actions

- Awareness: campaigns and civic education.

The center performs actions oriented to improve tasks on data collection and sharing to the public in a clear way. The main sources of data are remote sensors in the field, satellite imageries, radars, and geographical information.
Big data is feeding continuously all the serves in the center. This data needs to be processed into different tasks to generate early information, forecast information, and other tasks related to assessment.

\section{Method}

The country of interest for this study was El Salvador, located in the Pacific coast of Central America (tropical climate). The geographical characteristic of El Salvador, located in the tropical climate zone and in the Ring of Fire, makes the country to be in a constantly zone risk to natural hazards. Besides this, meteorological events affects the country year by year.

The research is based on the case of the Ministry of Environment and Natural Resources of El Salvador (MARN for its acronym in Spanish) that has performed various actions in monitoring disasters by locating automated sensors in the field as well as upgrading the instruments continuously. The telemetry technology has started to be one of the main system for data collection.

The implementation of geographic information systems (GIS) is one of the tool to manage data. Among this, different software classified in principle as an open or proprietary source exists. For the monitoring center such a software is one of the main bases for the daily tasks that needs to be accomplished.

The research explain the different tools that combine the use of open source software and proprietary software to develop applications that are easily understood by people and offers easy access and transmission in real time, tasks on data collection and sharing to the public in a clear way. The main sources of the information has been provided by developers involved in the monitoring center develop application to manage big data, and to generate product such as maps with different characteristics for different purposes (rainfall, soil moistures, landslide, geological characteristic). Additionally, lessons to learn from developed countries, taking the plans performed by the Korean government.

This theoretical bases were analyzed in order to establish relationships, differences, stages, or the current position of the knowledge we have about managing EWS implemented for monitoring natural hazards. To propose an integrated and comprehensive system, sharing information in the shortest time possible, and achieving a big database available to make risk assessments would be the main goals of such a system.

\section{Early warning systems applications and management in El Salvador}

It has been known that for the recent year the implementation of geographic information systems (GIS) is one of the tool to manage data. Among this, different software classified in principle as an open or proprietary source 
exists. For the monitoring center such a software is one of the main bases for the daily tasks that needs to be accomplished. The center has started to use different tools that combine the use of open source software and proprietary software to develop applications that are easily understood by people and offers easy access and transmission in real time. As an example, online land information system is operating in a decentralized manner with updated information since 2010. The information basically includes: flood risks status, landslide risk, droughts, tsunamis, earthquakes and volcanic eruptions.

\section{Designing a system to manage and communicate} information of the natural disasters situation in El Salvador Earlier, the areas that elements and devices are needed within the natural hazards context in El Salvador has been described. Different experts in the fields involved in the monitoring center develop application to manage big data, and to generate product such as maps with different characteristics for different purposes (rainfall, soil moistures, landslide, geological characteristic). An application named WorkStation was develop to integrate the information from the Natural Hazards Monitoring Center and the Environmental Monitoring. The elements of the system are:

- Management and decision making: oriented to the high level decision makers.

- Workstation: groups formed by specialists and technicians responsible for the natural hazards monitoring.
- Information dissemination: services and tools to obtain information that are geared for the general public.

A system engineer works on the tasks of developing applications. His objectives are to improve the storage data structure by adding space capabilities, to design the user interface and to build the software [10]. Following a methodology lifting requirements, modifications to existing databases, interface design and coding are also required. Additionally, data structure design, user interface design and mobile interface design are of main importance. (See Fig. 4.Platform for data collection and storage).

As an outcome, the platform displays information as a country base map with different shapes to define the locations of the telemetric station network information in a graphical way. The internal process are set to display registered rainfall, river levels variations, landslide susceptibility, radar images and different other graph with the processed data. The information is updated on real time indicating rainfall amount variations, river fluctuations, rainfall radar images, landslides and flood susceptibility (see Fig. 5. Workstation System).

\section{Mobile applications for the dissemination of information to the population}

In the previous sections an application utilized mainly for the internal process in the monitoring center was described. However, the institution decided to share with the population specific information to maintain updated information and make faster response in different ways. A

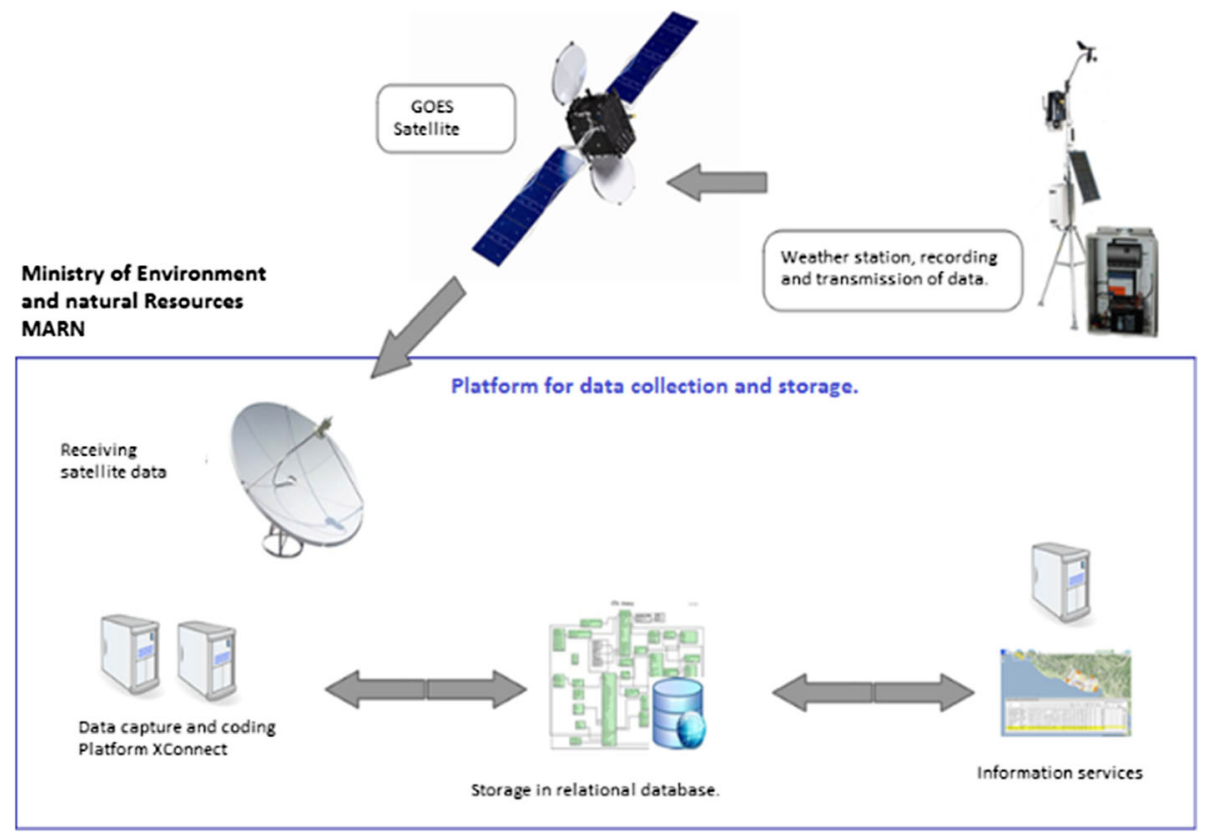

Fig. 4 Platform for data collection and storage. Source: Martinez C. [13] 

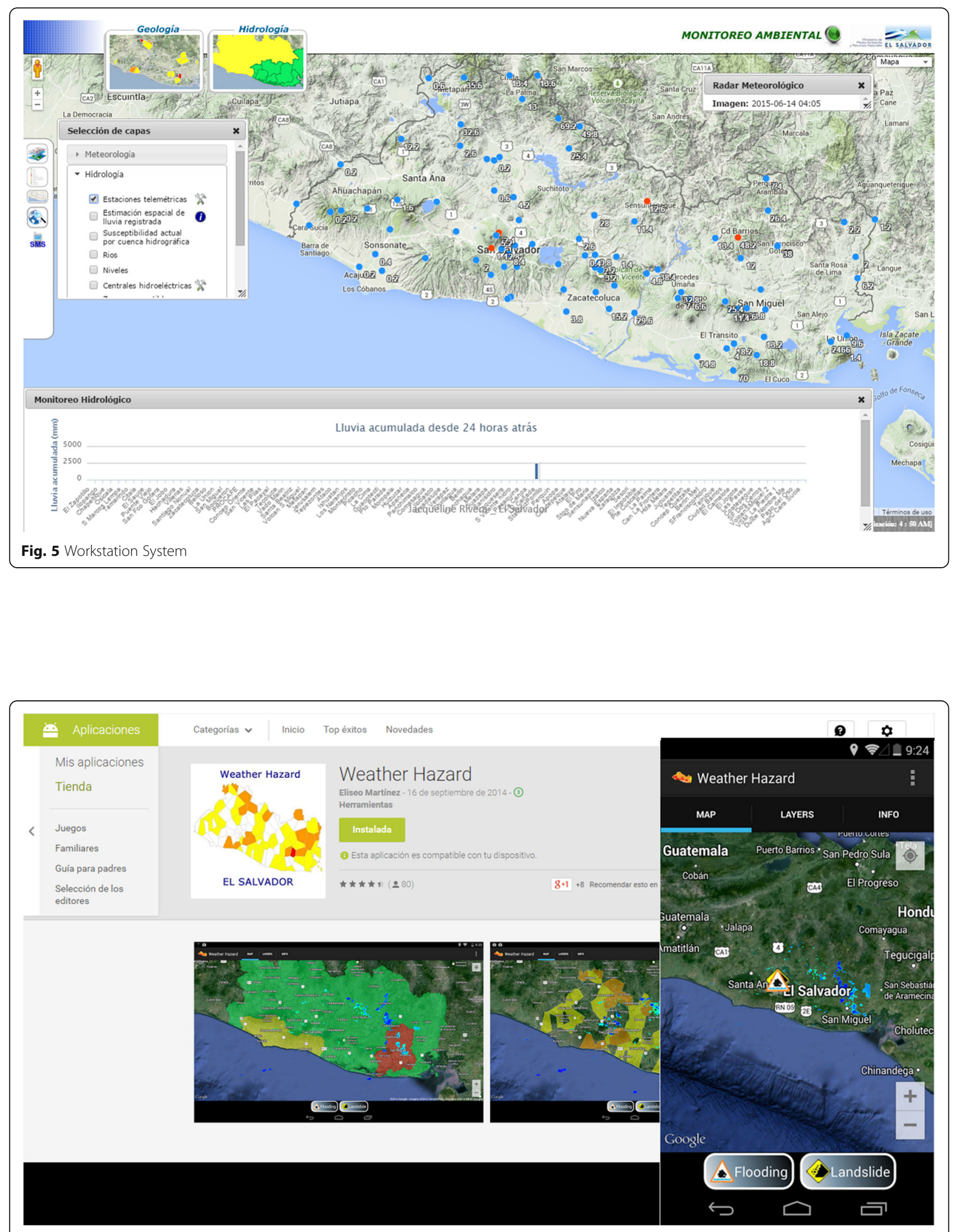

Fig. 6 Weather Hazard Platform 
set of mobile applications created with information from early warning systems was developed to share information related to natural threats in the shortest time possible.

\section{Weather hazard app}

Weather Hazard mobile application is a real time flood and landslide warning system for El Salvador. It is an android application created in principle for global app development competition (GEO Appathon 2014) and to develop useful tools for Salvadoran users (see Fig. 6).

This product is a combination of both Global Earth Observation System of Systems (GEOSS) and MARN datasets. The data on the GEOSS portal, is an entry point to earth observation data from all over the world. The GEOSS portal is a large metadata base service containing resources of agriculture, biodiversity, climate, disasters, ecosystems, energy, health, water as well as weather data. Furthermore, data coming from the reports of the users (citizen report) were also included in the app. The implementation characteristics include:

- Google App Engine: Google App Engine is a platform offered as a service (PaaS) that allows building and running applications on Google's infrastructure.

- Weather Hazard uses App engine to store citizen reports and process WMS tiles to add transparency to tiles.

- Frontend: The App was developed using Eclipse ADT and Standard Android APIs + Google Maps API for Android V2. Main UI composed of a Tabbed Activity.
Warning message App. Alertas @MARN.SV V2.0 - android app The warning message application is a push notifications app developed for Android devices. The application was created to disseminate notifications and alerts generated in the monitoring center of the Ministry of Environment and Natural Resources of El Salvador.

The notified information includes the ongoing monitoring state of the San Miguel volcano activity, susceptibility to landslides, hydrometeorological monitoring, air quality, and other information related to natural hazards $[11,12]$.

The application was originally designed as an internal communication tool within the monitoring center. However due to the characteristics of the information, is considered as a public interest tool. (See Fig. 7. "Alertas MARN" Plataform).

\section{Dissemination if the volcanic activity. Monitoreo VSM}

The original product is a web app designed for TV Screen (32"). It is a tool implemented in the monitoring center and the municipalities surrounding the volcano. (See Fig. 8. Volcano Monitoring. Original application)

To implement in mobile and Windows Store App, Bootstrap was used as CSS Framework (Grid system + some components). The rest of the code was reused from the existing App. The app was developed utilizing Apache Cordova.

Apache Cordova is a platform for building native mobile applications using HTML, CSS and JavaScript. Using this platforms represents an opportunity to take advantage of the written codes for the web to make available on mobile devices.

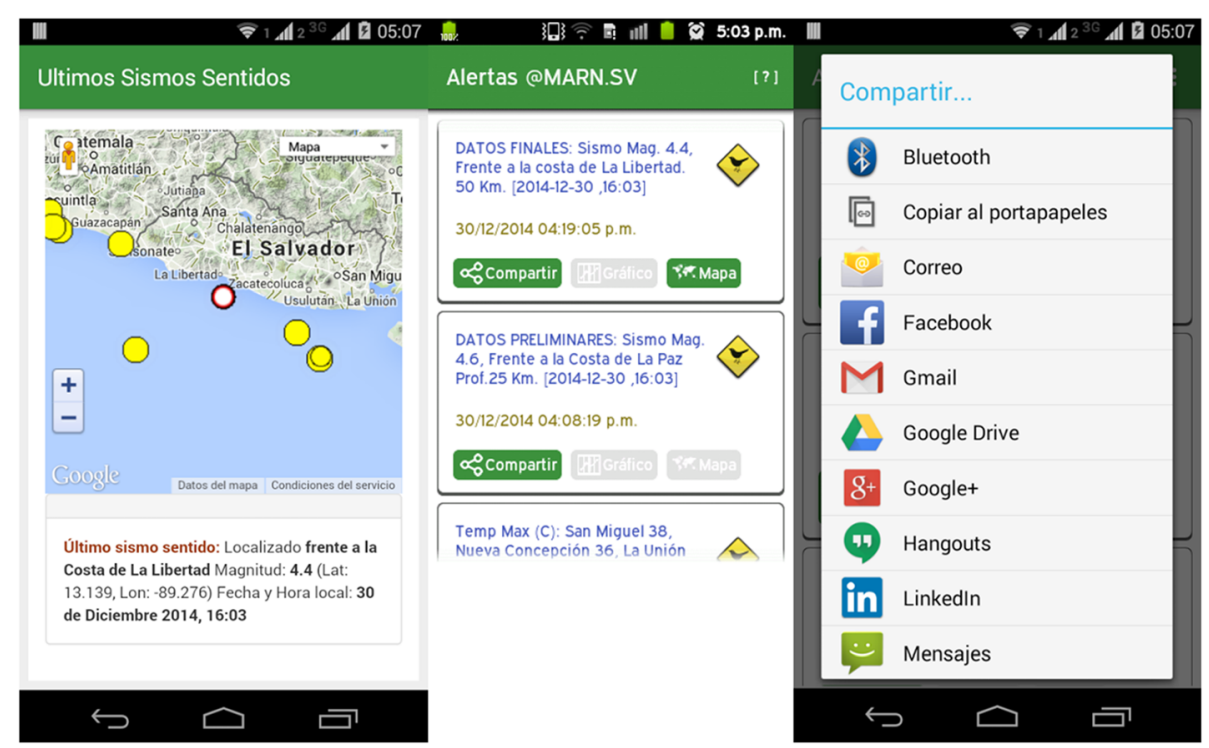

Fig. 7 "Alertas MARN" Plataform 

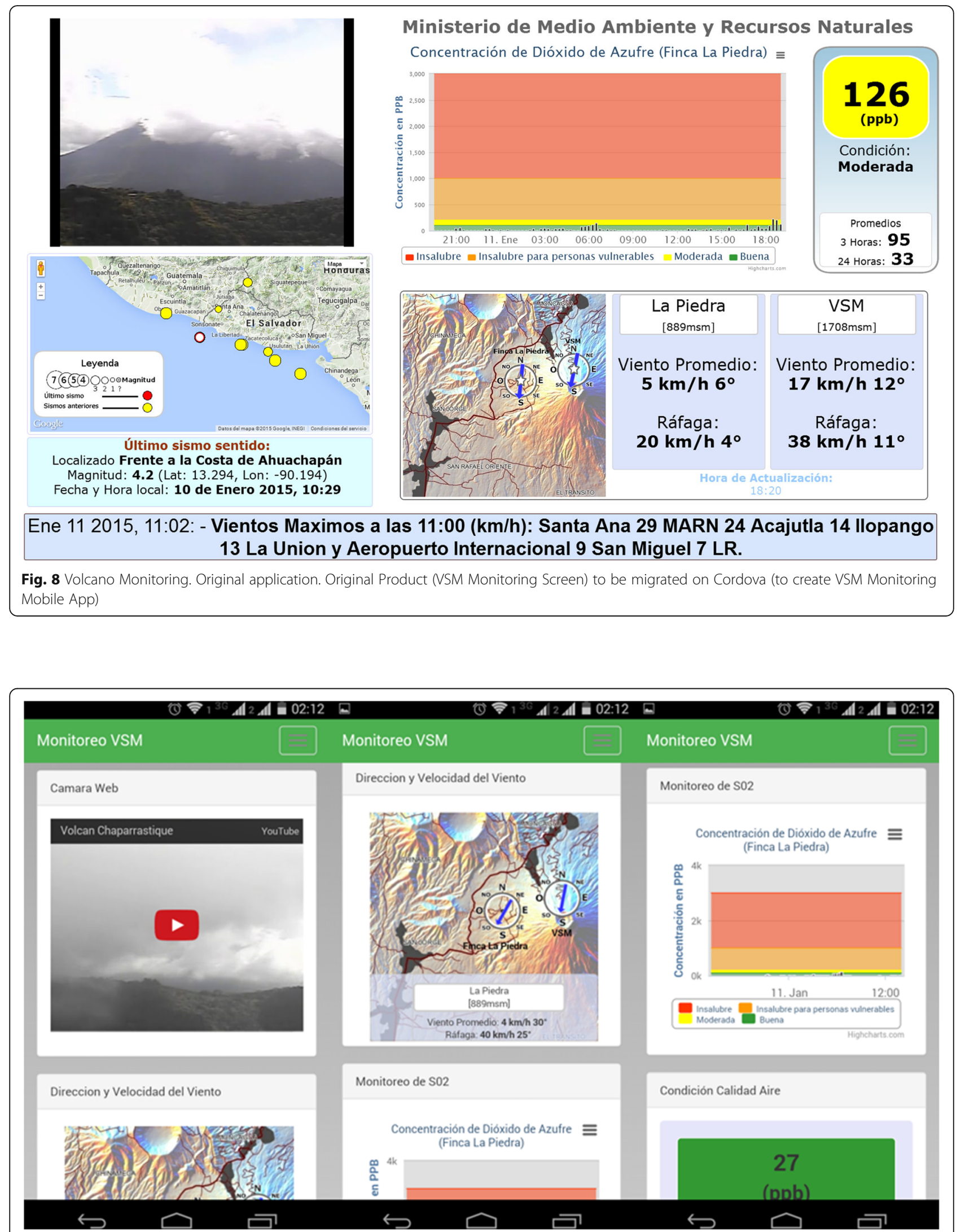

Fig. 9 Volcano monitoring app for mobile 


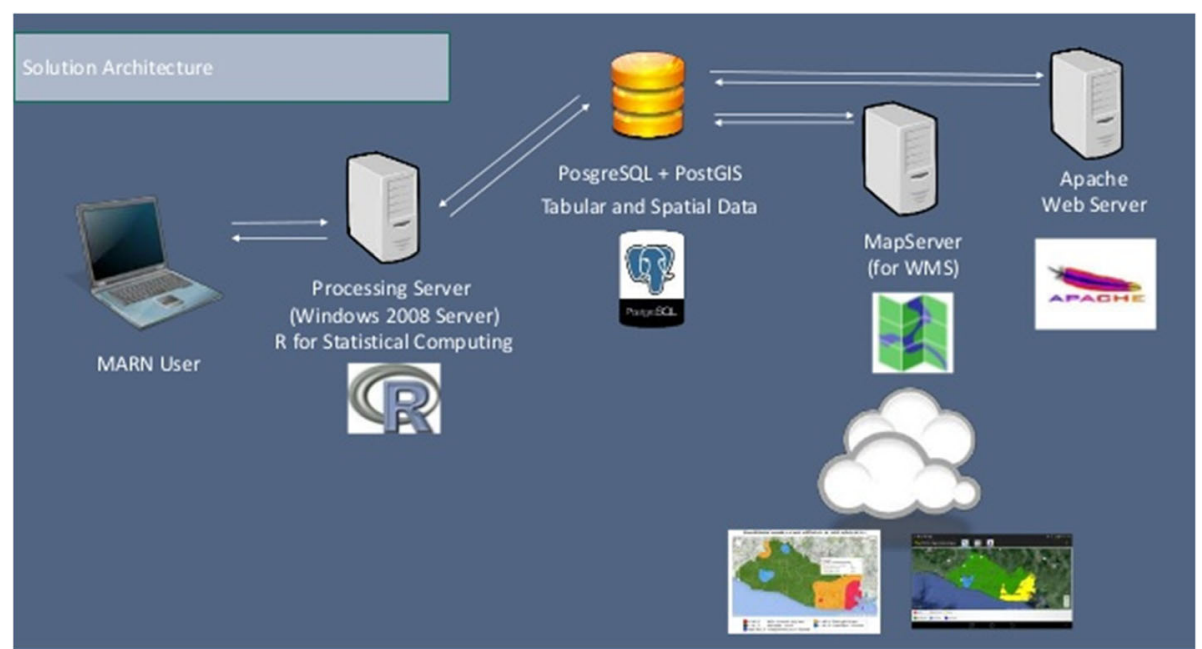

Fig. 10 Agrometeorological application architecture. MARN Agrometeorología. Souce http://www.slideshare.net/DavidEliseoMartinezC/marnagrometeorologia

The application is maintaining informed by the people about the volcanic activity (San Miguel Volcano). They receive the information in real time. Besides, the warnings by the official institutions of national and local government are issued. (See Fig. 9. Volcano monitoring app for mobile.)

\section{Agrometeorological data dissemination}

MARN publishes bulletin about crop condition and agrometeorological information, including a map of estimated soil moisture. To share this information a web mapping application as well as an Android mobile application was developed [13].
The map is an estimation of the soil moisture. The soil moisture amount is a calculation done by agro climatic expert and GIS technicians. MARN facilitates the automation of the generation of this map as part of a new drought monitoring system.

The system architecture of MARN contains different elements related each other such as PosgreSQL + PostGIS Tabular and Spatial Data, Apache Web Server MapServer (for WMS), and R for Statistical Computing. (See Fig. 10. Agrometeorological application architecture. MARN Agrometeorología.)

The database is a compilation of different geographical points containing soil moisture information. The data is processed in $\mathrm{R}$ framework that executes a spatial

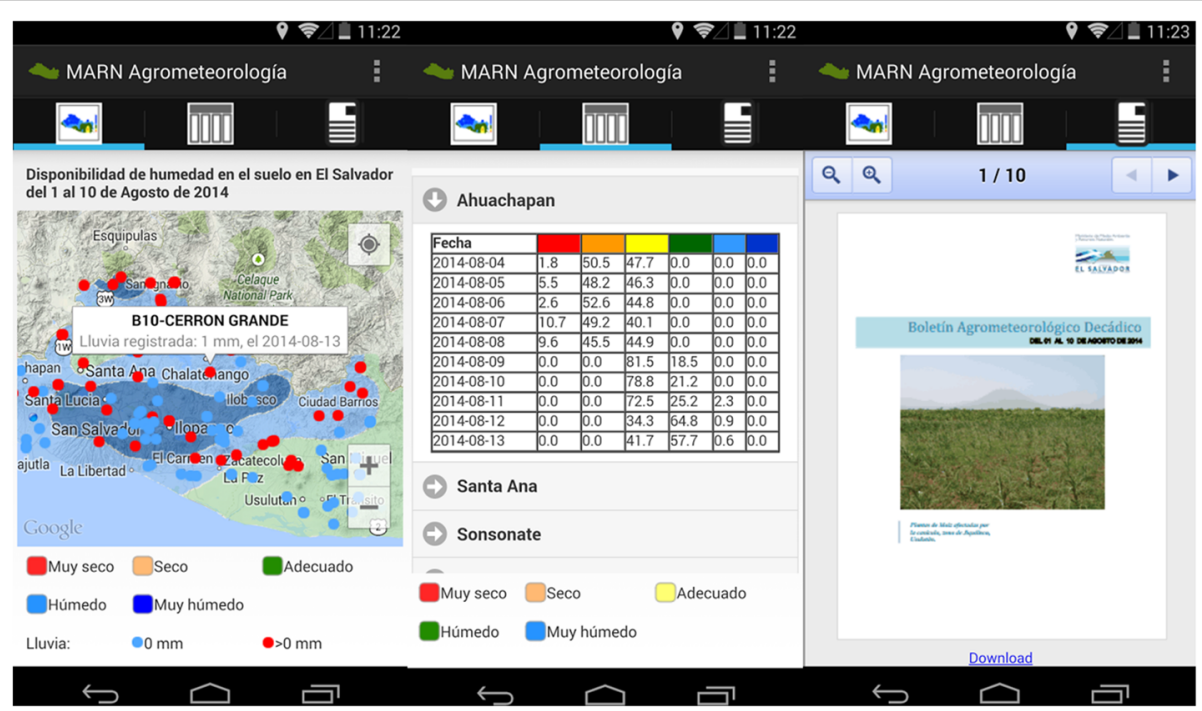

Fig. 11 Agrometeorological Mobil Application 


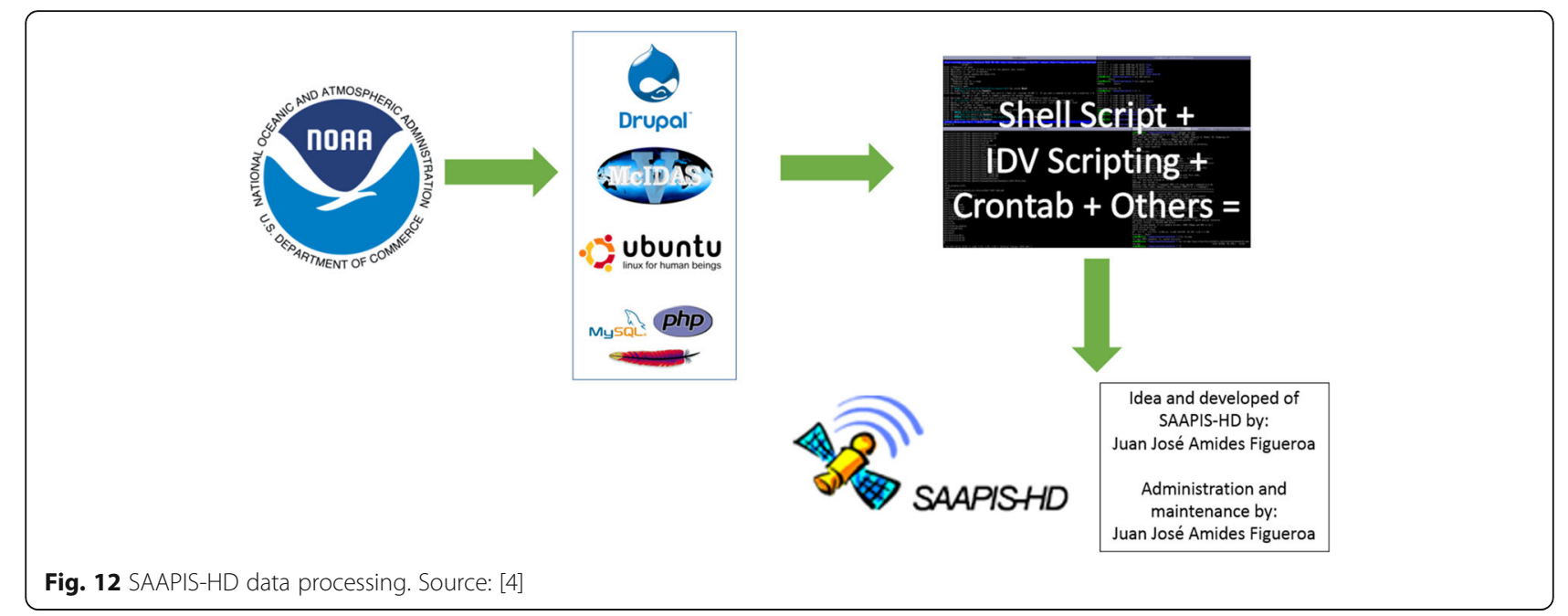

Interpolation (ordinary kriging), reclassification, and calculates and stores the result in the geo-database (PostGIS). Once the data processing is done, the final results are presented in a web map developed using PHP, JavaScript + jQuery, and Google Maps API for JavaScript.

The mobile application displays agrometeorological monitoring information (see Fig. 11. Agrometeorological Mobil Application). The app allows to share pictures and comments from the citizen reporting the crops status. Additionally, other contents are available:

- Daily map soil moisture, updated daily at 11:00 am

- Map of soil moisture based on 10 days.

- Daily Record of rain in the rainfall network of El Salvador.

- Decadal agrometeorological report.

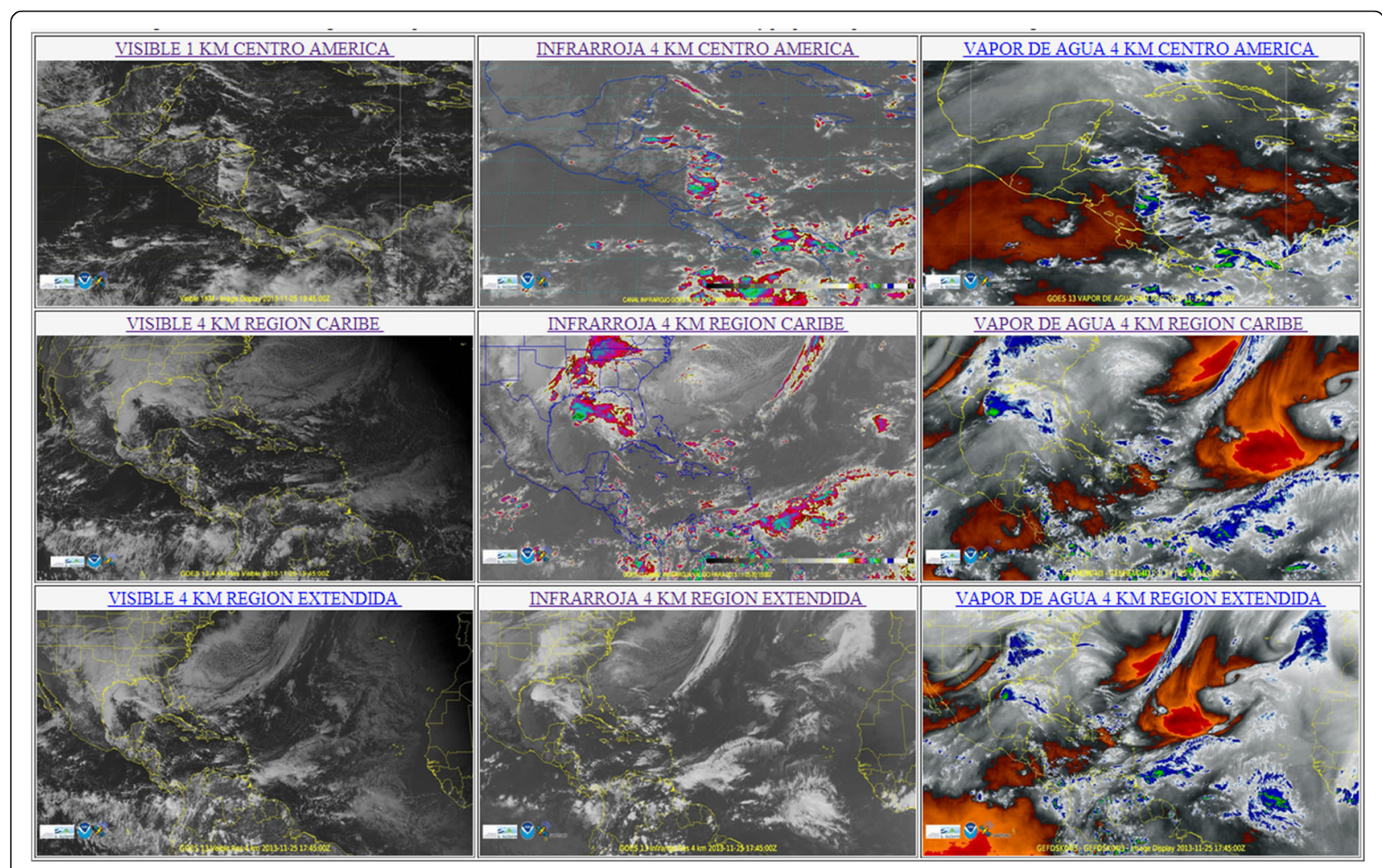

Fig. 13 SAAPIS-HD products. Source: [3] 


\section{Automated system for acquisition and processing of satellite images in high definition (SAAPIS-HD)}

The Automated System for Acquisition and Processing of Satellite Images in High Definition was developed to provide access to satellite images and HD resolution for meteorological products, storage raw data for future research and case studies, as well as to generate high quality images and meteorological products. In addition, improving accessibility to information for everyone in the area of meteorology is an advantage provided by this system.

SAAPIS-HD is a set of free programs, scripts and configurations synchronized to generate satellite imagery from the NOAA GOES-13 satellite. The system is based on software visualization and analysis of McIDAS-V data at version 1.3, set to run in Ubuntu 10.04 LTS Lucid Lynx system and controlled by scripts that run all processes [4].

The set of procedures consist on data acquisition, processing, product processing, storage and presentation. The processes are done through an html interface, Drupal content management system mounted on an Apache / MySQL server. (See Fig. 12. SAAPIS-HD data processing)

The system is able to generate images for the analysis of meteorological variables based on the NOAA GFS 0.5 degrees. Capable to generate images for the analysis of meteorological variables based on local data from the mesoscale model WRF. (See Fig. 13. SAAPIS-HD products).

These tasks seek to fulfill the performance of numerical operations using the data obtained from the satellite images. The library PyQGIS in QGIS to execute Python code could be a tool to accomplish tasks that require periodic calculations. The advantages are the processes automatization, simplicity in creating plugins in QuantumGIS and fulfill the specific needs of data analysis.
Automatic numerical modeling of mesoscale system with the weather research and forecast model - WRF (SMNM -WRF)

Weather Research Forecast Model (WRF) is a meteorological numerical model with Non-hydrostatic and mesoscale hydrostatic option. The model is utilized for operational as well as research purposes. The Automatic Numerical Modeling of Mesoscale System with the Weather Research and Forecast Model (SMNM -WRF) is a self-contained system, it does not need human intervention to run the weather research and forecast model. Running under Ubuntu 10.04 LTS Lucid Lynx system and using scripts, the WRF data is created by different institution related involved in the meteorological field. ${ }^{3}$ [3].

The final stage of the model consist in generate imageries to be published and utilized for analysis processes. The data related to El Salvador is done by the meteorological area in the monitoring center:

- ARWpost: to convert the output of the WRF to GrADS

- GrADS: to export results into images for publication and analysis

The tool ARWPost tool produces images for the analysis of meteorological variables with GRADS software, these products are presented through an html interface using the Drupal (content management system) mounted on an Apache / MySQL server. (See Fig. 14. Maps produced by the SMNM -WRF.)

\section{Central America Flash Flood Guidance (CAFFG)}

Most of the previous tools described are related to sharing information for in a user friendly way for the population. In previous section, an application for the meteorological areas were presented. The next tool is related to the

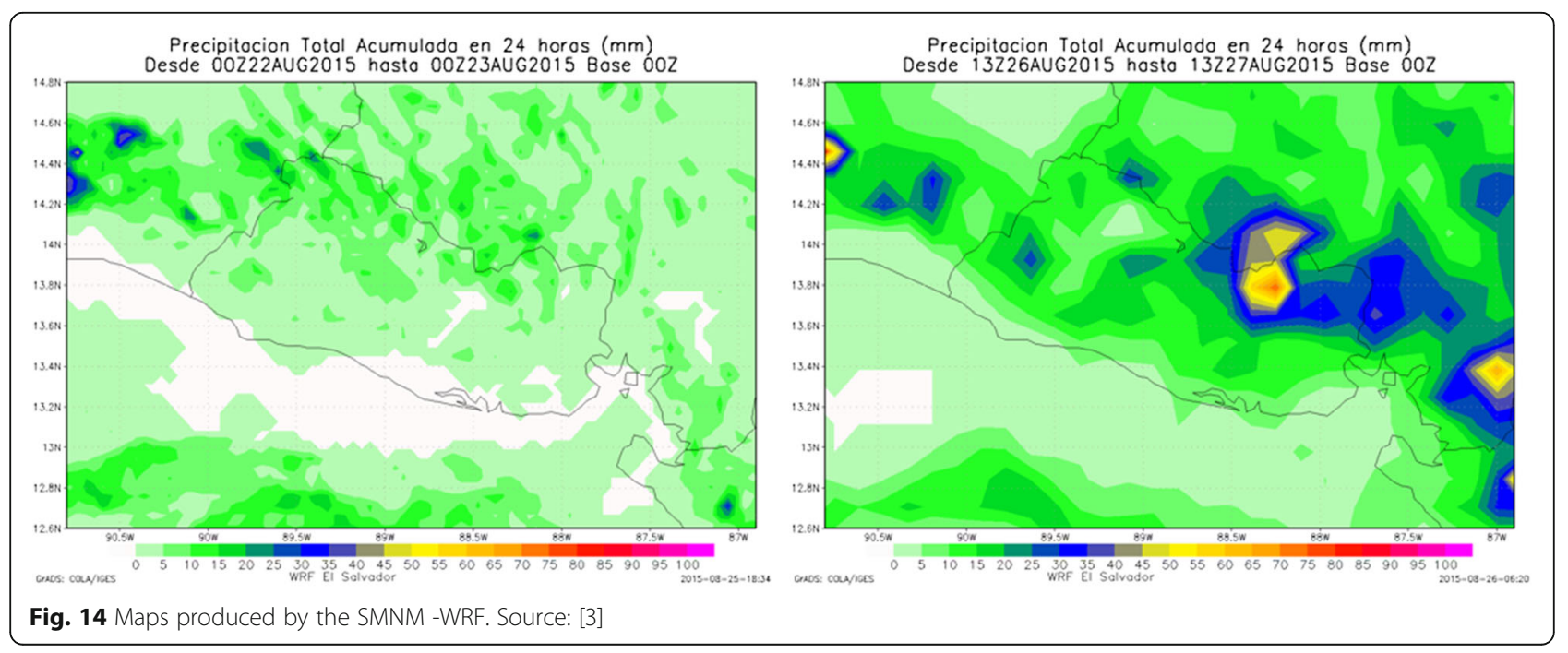




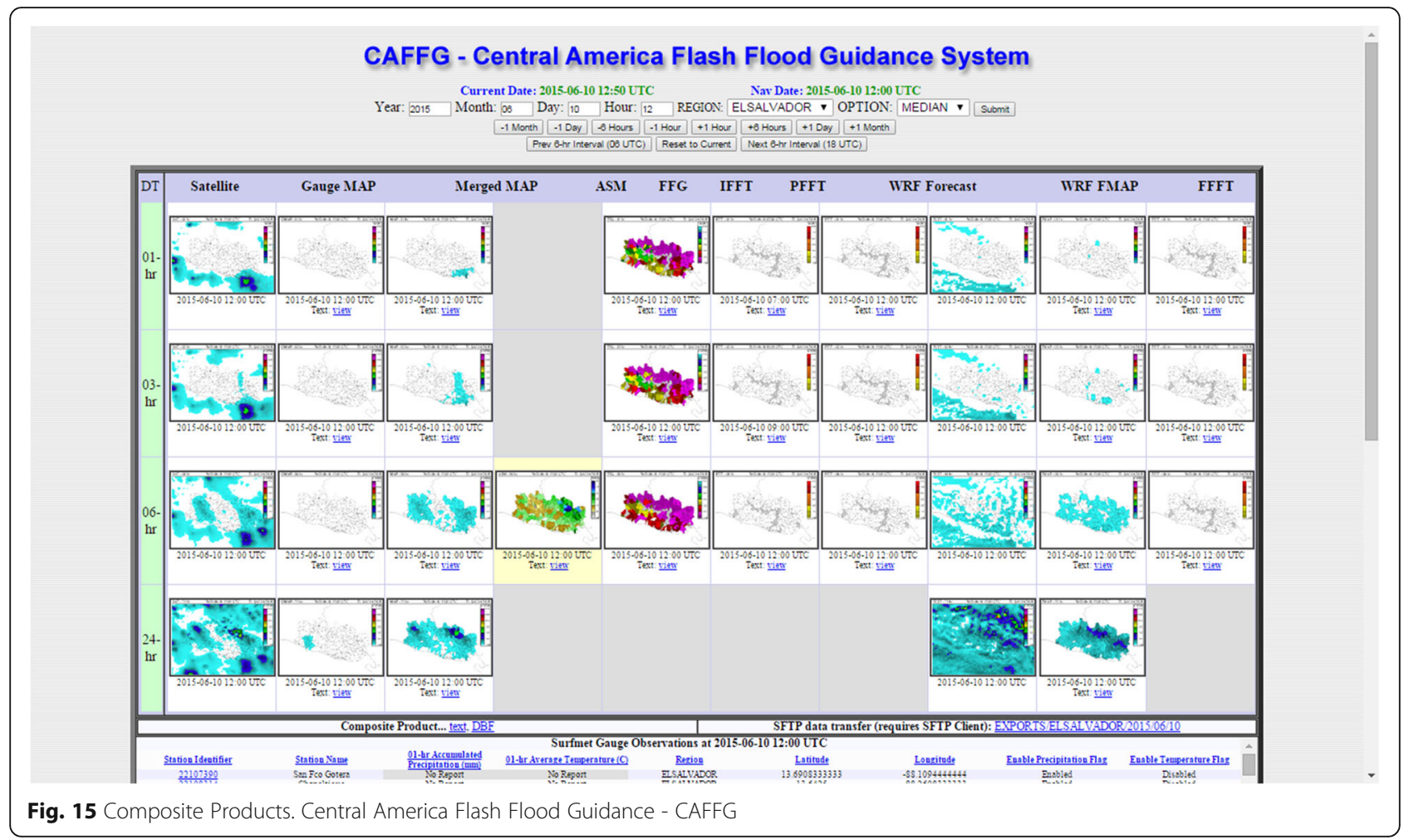

actions performed by the hydrological area implemented in the Central America Flash Flood Guidance (CAFFG). The CAFFG is an early warning system for floods developed by the Hydrologic Research Center (HRC) that allows Central American countries to forecast flash floods in small streams draining areas.
The CAFFG comprises three models: the soil moisture model [5] the threshold runoff model [2], and the flash flood guidance model [6]. The system provides images and text related to estimated and forecast precipitation products. The information comes in imagery and numerical data, it has been developed to work areas with $130 \mathrm{~km} 2$

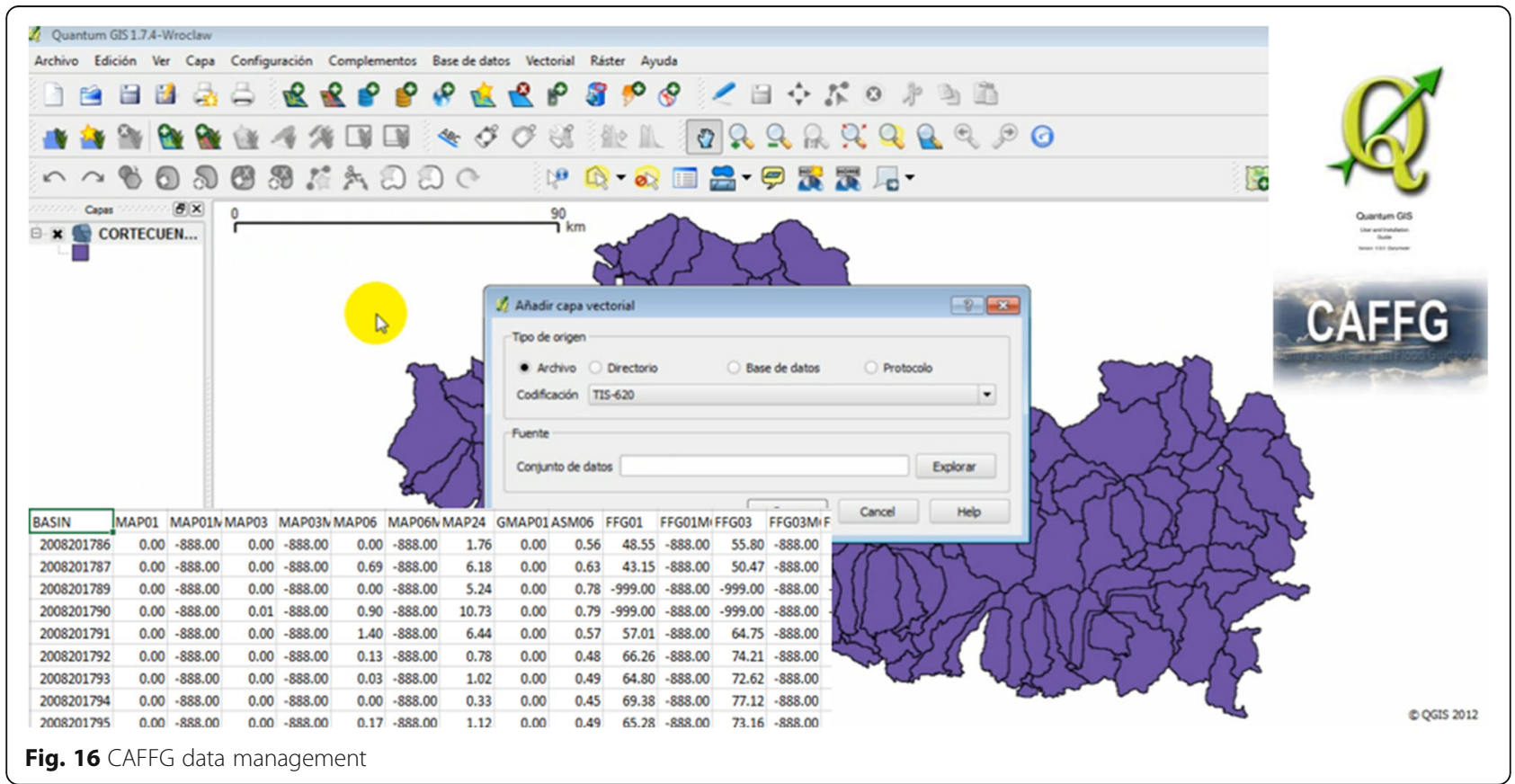




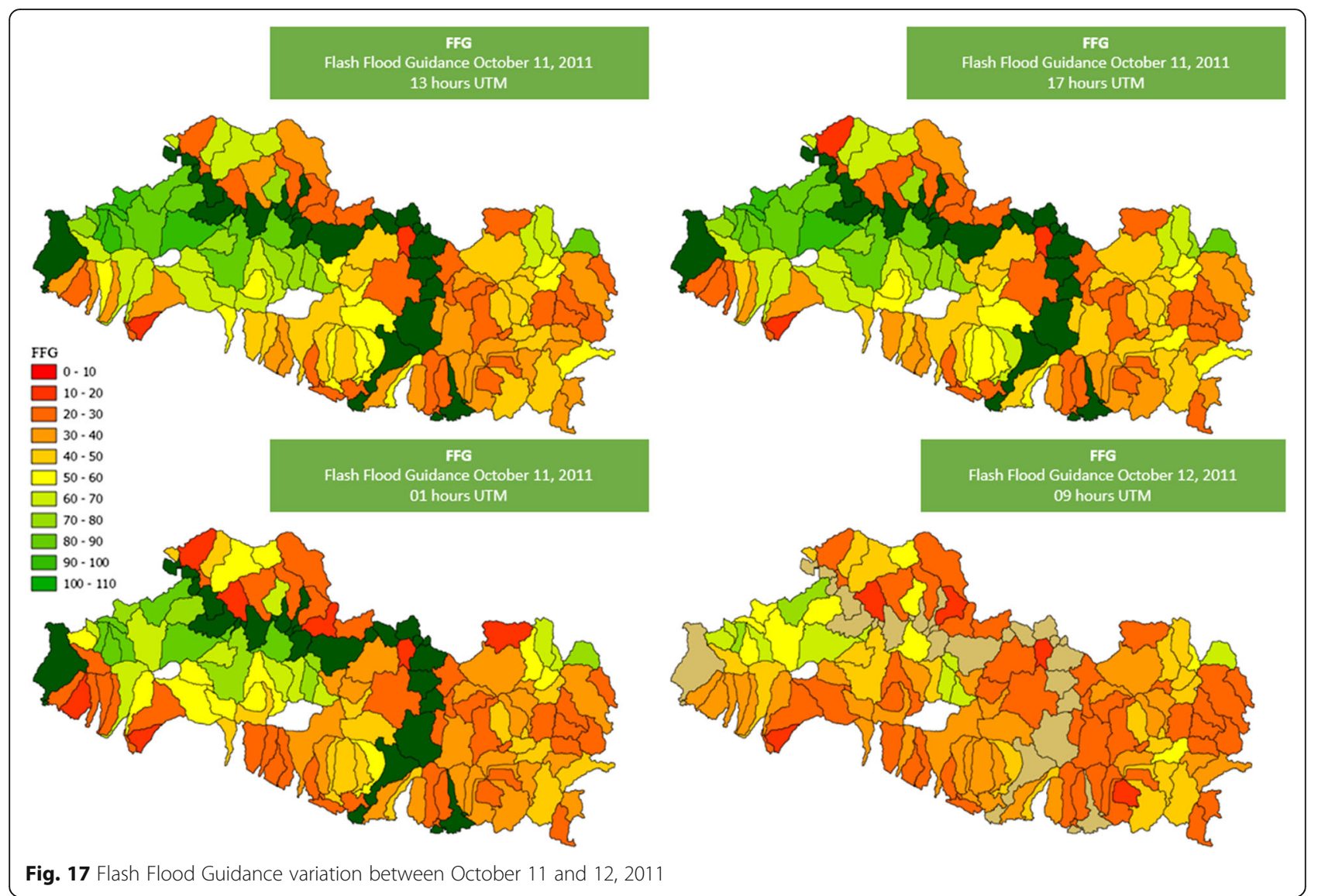

with high resolution. (See Fig. 15. Composite Products. Central America Flash Flood Guidance - CAFFG)

The primary system product is the Flash Flood Guidance amount (FFG). FFG is the rainfall amount needed to cause bank full at the end of the basin. The users can leverage that information in their efforts for quality control and in their assessments to further apply the FFG data in their operational forecasting activities [8]. (See Fig. 16. CAFFG data management). The data generated by the system is handled primarily in the QGIS platform, for database adjustments and handle graphics in specific periods of time and locations. (See Fig. 17. Flash Flood Guidance variation between October 11 and 12, 2011).

\section{Discussion and conclusions}

Countries exposed to different natural hazards such as El Salvador have to introduce and implement certain technologies for monitoring and taking comprehensive actions. The actions are mainly reflected in the creation of strategies based on EWS implementation for natural threats monitoring. Since natural hazards are also one of the most important challenges in land development, enhancing the actions is an important issue to solve. Therefore, we discuss two case examples to elaborate on the importance of this study.

\section{Korean case as an example of monitoring integrated systems}

Lessons to learn from developed countries such as the Korean case exists. According to information by the Korea Research Institute for Human Settlements (KRIHS), the Korean government has established normative and specific application of GIS in the field of data management. The main normative to mention are:

- Law that creates a National Geographic Information System: forces digitalization of the nation's public information and establishes GIS standardization.

- Implementation of the law in all government levels.

The specific application of GIS include:

- Geographic data: digitalization of topographic and cadastral maps. Construction of framework data such as roads, rivers, etc.

- Application systems: development of GIS application systems such as land use, environment, marine, etc. Example: KLIS and KOPSS, facilitating data sharing and interoperability.

- Standardization: GIS standardization for national mapping, distribution systems, etc. 
- Technologies: development of mapping, Databases, 3D GIS (urban planning, flood simulation, navigation), high-resolution remote-sensing images, etc.

- Research and development: inter-connections among fields, construction of user oriented to National Spatial Data Infrastructures (NSDI). NSDI as a basis for National Growth Impetus, Social Infrastructure for Smart Society and Basis for National Government Administration.

\section{Case study facts for El Salvador}

The concerns from the institutions to include information from the field into geographical information systems is becoming an essential action to strengthen and speed up the response to an imminent threat. Specially creating strategies supported by national plans such as risk reduction national plans, and climate change national plans among others. To develop an effective EWS in El Salvador three main aspect are required:

- An integrated system to make the data easily available.

- Considering the tools to manage the big amounts of data generated by this systems. Nowadays, open source software are becoming more used and capable to develop complex process required for natural disasters evaluation.

- Data dissemination: to inform the population under an imminent natural disaster to take preventive actions in the shortest time possible.

In this context, the Natural Threats Integrated Monitoring Center established by the Ministry of Environment and Natural Resources in El Salvador is taking big steps towards the field of EWS. Despite the fact that El Salvador is a developing country, the first steps have been performed to form an integrated system. However, more actions has to be conducted.

\section{Results}

Focused in EWS and data management integration, the aim is to involve all the institutions related to risk management and create a system for monitoring natural hazards. Creating an integrated and comprehensive system, sharing information in the shortest time possible, and achieving a big database available to make risk assessments would be the main goals of such a system. (See Fig. 18. Comprehensive approach for integrated EWS)

The first needs that have raised in this field in El Salvador is the digitization as well as improving application systems, and standardization of the data among the different institutions.

Mainly the information that needs to be captured and digitized are the census, housing vulnerability, rural towns, etc. The GIS standardization for all the different types of data needs to be done in order to make a fluently data sharing and interoperability for an easy public data accessibility. However, from this needs it arises the necessity of more in situ sensor installments (See Fig. 19. Comprehensive approach for integrated EWS).

A comprehensive approach implies to establish monitoring centers to integrate different social areas, essential issues such as security, transportation, taxation, etc. Comprehensive plans involve different institutions, privates and publics. Besides, cadastral and census information can be included in different task, economical estimate of losses after a disaster, infrastructure losses, etc. Involving central and local government institutions.

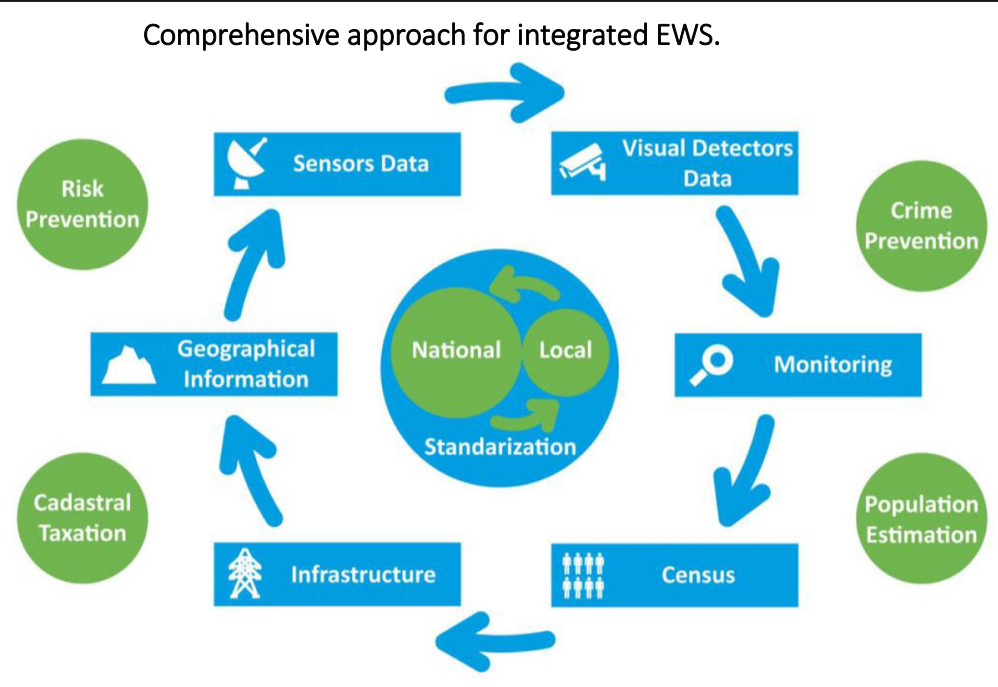

Fig. 18 Comprehensive approach for integrated EWS 


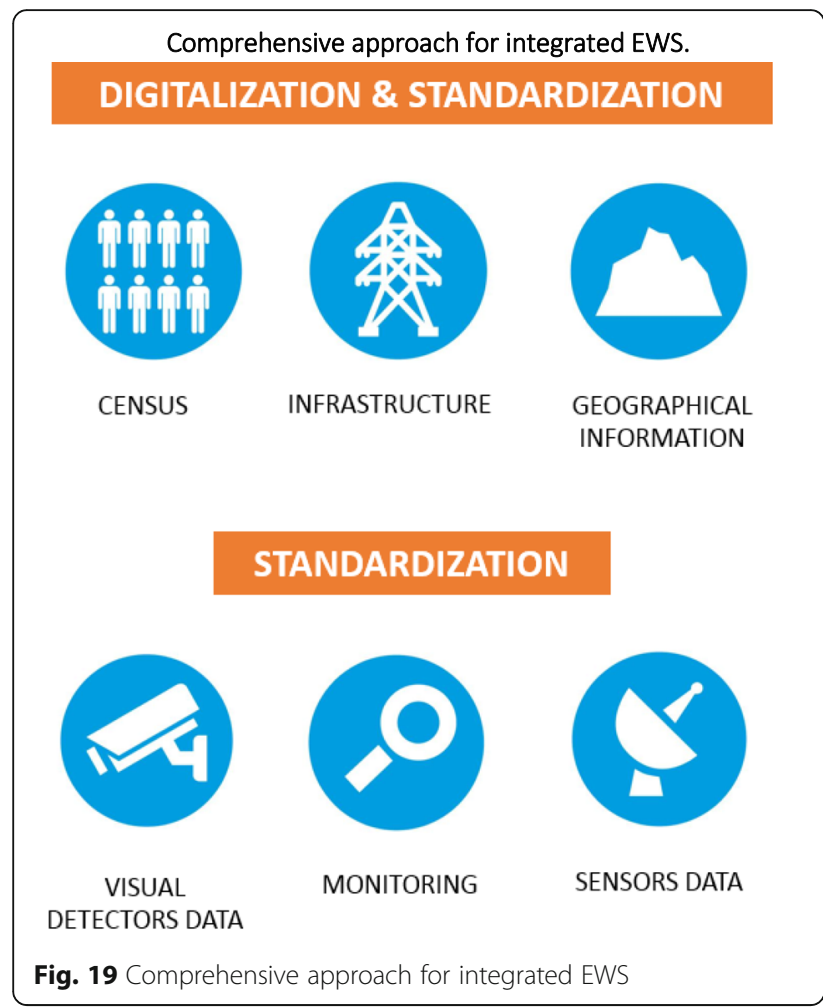

\section{Future work}

The progress performed during the last years in $\mathrm{El}$ Salvador on the management of big data set for issues related to monitoring natural threats, receiving real-time data, processing these data to generate information in a timely manner to alerts the populations exposed to a high risk for a threat is remarkable.

Other important aspect achieved is the automatization of different systems and platforms displaying graphical information in improving the interpretation and sharing information with the population in a fast and understandable way.

The next steps towards different software applications that include the use of geographic information systems are the tasks to develop forecasting products. The forecast product are not only related to the meteorological field, but also includes both floods and landslides forecasts produced by excessive rainfall.

The hydrological area have been performing tests for the implementation of free access hydrologic analysis platforms that offers stable and complete tools for this analysis. One of this platform is HEC HMS that can integrate different data inputs as those mentioned in the previous sections (such as rain forecast) and perform hydraulic analysis using the HEC RAS platform. HECHMS and HEC-RAS have been developed by the U.S. Army Corps of Engineers, available to the public as open source.
Besides, on the prediction of occurrence of landslides other studies using various platform have been done. One of the used platforms is LAHARZ for lahar-inundation modeling in a GIS environment. Taking into account different variables to characterize the terrain.

All these free platforms offer constantly more tools for modeling and forecasting tasks, becoming applicable in the institutions responsible for monitoring natural threats such as the Monitoring Center. Those areas (hydrology and geology) and their respective software that was mentioned are the next processes of scientific research to be studied and employed to be used for the purpose of forecasting.

\section{Endnotes}

${ }^{1}$ The Ring of Fire is an area in the basin of the Pacific Ocean where a large number of earthquakes and volcanic eruptions occur.

${ }^{2}$ The damages cost is around US $\$ 1.3$ billion, when the national annual GDP is around US\$23 billion.

${ }^{3}$ The WRF was developed by: NCAR (National Center of Atmospheric Research), NOAA/ESRL (Earth System Research Lab), NOAA/EMC (Environmental Modeling Center), and others Institutes and Universities.

\section{Abbreviations}

ASM, average soil moisture; CAFFG, Central America Flash Flood Guidance; CSS, cascading style sheets; EWS, early warning systems; FFFT, forecast flash flood threat; FFG, flash flood guidance; FMAP, forecast mean areal precipitation; GDP, gross domestic product; GEO, group on earth observations; GIS, geographical information systems; GMAP, gauge mean areal precipitation; ICT, information and communication technology; IFFT, imminent flash flood threat; MAP, mean areal precipitation; MARN, Ministry of Environment and Natural Resources in El Salvador (Ministerio de Medio Ambiente y Recursos Naturales in Spanish); PFFT, persistence flash flood threat; SAAPIS-HD, automated system for acquisition and processing of satellite images in high definition in spanih Sistema Automatizado para la Adquisición y Procesamiento de Imagines Satelitales; SMNM -WRF, automatic numerical modeling of mesoscale system with the weather research and forecast model in Spanish of Sistema Automatizado de Modelación Numérica de Mesoescala; UNISDR, United Nations office for disaster risk reduction; WMS, web map service; WRF, weather research forecast model

\section{Acknowledgements}

I would like to thank to the Ministry of Environment and Natural Resources of El Salvador, the director of the Monitoring Center for Natural Hazards Celina Kattan and the engineer from the center Miguel Alvarenga, for the support to expose the existent actions for risk prevention. Special thanks to the application developers David Eliseo Martinez Castellanos and Juan Jose Figueroa Amides Urbano, for sharing all the information about the different applications for the data management and analysis. Finally, I appreciate the collaboration of the Hydrologic Research Center (HCR), and CAFFG developers.

Received: 15 June 2016 Accepted: 19 July 2016

Published online: 09 August 2016

\section{References}

1. Basher R. Global early warning systems for natural hazards: systematic and people-centredP. Philos Trans R Soc. 2006;364(1845):2167-82.

2. Carpenter, TM, Sperfslage JA, Georgakakos KP, Sweeney T, Fread DL. National threshold runoff estimation utilizing GIS in support of operational flash flood warning systems. Journal of Hydrology. 1999;224:21-44.

3. Figueroa, J. J. Automatic Numerical Modeling of meso scale System with the Weather Research and Forecast Model (WRF). 2015b. Retrieved from Researach Gate: http://www.researchgate.net/publication/259368195_ 
Automatic_Numerical_Modeling_of_meso_scale_System_with_the_ Weather_Research_and_Forecast_Model_\%28WRF\%29.

4. Figueroa., J. J. Research Gate. 2015a. Retrieved from Research Gate: http:// www.researchgate.net/publication/259368556_Automated_System_for_ Acquisition_and_Processing_of_Satellite_Images_in_High_Definition_or_ SAAPIS-HD.

5. Konstantine P. Georgakakos, Diane E. Smith. Soil moisture tendencies into the next century for the conterminous United States. Journal of Geophysical Research. 2001;106:27367-27382.

6. Georgakakos K P. Analytical results for operational flash flood guidance. J Hydrol. 2006;317(1-2):81-103.

7. GFDRR. Global Facility for Disaster Reduction and Recovery. (n.d.). https:// www.gfdrr.org/core-documents.

8. Hydrological Research Center, HCR. Central America Flash Flood Guidance. 2015, de HCR. 2011. Website: http://www.hrc-lab.org/right_nav_widgets/ realtime_caffg/index.php

9. ISDR, I. S. Third International Conference on Early Warning. Developing Early Warning Systems: A Check List, (p. 2). Boon, UNISDR: Germany;2006

10. Martinez C., D. E. http://www.slideshare.net/. 2015a. Retrieved from Slideshare: http://www.slideshare.net/DavidEliseoMartinezC/desarrollo-de-laestacin-de-trabajo-para-el-monitoreo-ambiental-y-monitoreo-en-tiempo-realde-la-depresin-tropical-12e

11. Martinez C., D. E. 2015b. Retrieved from Slideshare: http://www.slideshare. net/DavidEliseoMartinezC/weather-hazard.

12. Martinez C., D. E. es.slideshare.net/. 2015b. Retrieved from Slideshare: http:// www.slideshare.net/DavidEliseoMartinezC/alertas-marnsv-v20-android-app.

13. Martinez C., D. E. 2015c. Retrieved from Slideshare: http://www.slideshare. net/DavidEliseoMartinezC/marn-agrometeorologia.

14. Torres R. National Geological Service. 2015. Retrieved from http://www.snet. gob.sv/Geologia/Sismologia/1 vigsis.htm: http://www.snet.gob.sv/Geologia/ Sismologia/1vigsis.htm. Access date Nov 2015.

15. WDR. World Bank Report, 2015. 2015. 